Original Article

\title{
CAUSE-EFFECT RELATIONS AND OPTIMIZATION OF TABLET CONTAINING EUCOMMIA ULMOIDES AND GARDENIA JASMINOIDES SPRAY-DRIED EXTRACTS
}

\author{
VO THANH HOA, BUI THI THU HUONG, DO QUANG DUONG, NGUYEN DUC HANH*
}

Faculty of Pharmacy, University of Medicine and Pharmacy at Ho Chi Minh city, Vietnam

Email: duchanh@ump.edu.vn

Received: 03 May 2018 Revised and Accepted: 01 Jun 2018

\begin{abstract}
Objective: The E. ulmoides and G. jasminoides (EG) tablets containing $67 \mathrm{mg}$ E. ulmoides spray-dried extract (ESE) and $173 \mathrm{mg}$ G. jasminoides spraydried extract (GSE) were prepared by employing the direct compression method. Due to the poor flowability and compressibility of the two spraydried extracts, various excipients were added at different ratios so that the blends can be compressed into tablets with the required standards. This
\end{abstract} study aimed at the cause-effect relations and optimization of the EG tablet formulation.

Methods: Different diluents including dibasic calcium phosphate anhydrous (DCPA), silicified microcrystalline cellulose (SMCC), spray-dried lactose (SDL) and the active ingredients (blend of ESE and GSE at the ratio of 67:173, w/w) were separately investigated their own physical properties. The binary mixtures of the active ingredients with different ratios of DCPA, SMCC, and SDL were evaluated their flowability. D-optimal design based on three independent variables (\% DCPA, \% croscarmellose sodium (CCS) and \% SMCC) was applied to evaluate the cause-effect relations and optimize the EG tablet formulation. The weight variation, disintegration time, hardness and friability were investigated as four dependent variables.

Results: The flowability of the powders was found to be affected by the particle size distribution, particle shape and density. The three diluents could significantly improve the flowability of the active ingredients. All independent variables had significant effects on the dependent variables. An increase in \% SMCC reduced the weight variation, hardness and increased the friability of tablets. Disintegration time was found to be in the negative relations with \% CCS. The tablet hardness was in positive relations with \% DCPA. The optimized EG tablet formulation composed of $9 \%$ DCPA (w/w), $35 \%$ SMCC (w/w), and $14 \%$ CCS (w/w) of the excipient blend. The weight variation, disintegration time, hardness and friability of the optimized EG tablets were found to be $1.8 \%, 11.7 \mathrm{~min}, 61.4 \mathrm{~N}$, and $0.5 \%$, respectively.

Conclusion: The ESE and GSE could be formulated into tablet by using direct compression method. The cause-effect relations and optimization of EG tablet formulation were studied and reported for the first time.

Keywords: Spray-dried extract, Direct compression, Optimization, Cause-effect relations, BCPharSoft OPT software, Eucommia ulmoides, Gardenia jasminoides

(C) 2018 The Authors. Published by Innovare Academic Sciences Pvt Ltd. This is an open access article under the CC BY license (http://creativecommons.org/licenses/by/4.0/) DOI: http://dx.doi.org/10.22159/ijpps.2018v10i7.27099

\section{INTRODUCTION}

Tablets are solid dosage forms for drug delivery, representing twothirds of the global market due to the convienience of dosing, ease of manufacture, stability in comparison with liquid and semi-solid formulations [1]. Wet granulation, dry granulation and direct compression have been the three major methods for tablet preparation [2]. Of the three methods, direct compression is the more advantageous one due to its low cost, fewer unit operations, less time consumption, and low microbial level.

Eucommia ulmoides and Gardenia jasminoides extracts have been reported to possess anti-hypertensive activities associated with several mechanisms. In order to prepare the EG tablet containing $67 \mathrm{mg} \mathrm{E}$. ulmoides spray-dried extract (ESE) and $173 \mathrm{mg}$ G. jasminoides spraydried extract (GSE), the direct compression method was employed. In general, the spray-dried extracts are amorphous and tend to have poor physical-chemical properties [3]. Appropriate flowability is essential to ensure the homogenous and rapid flow of the tableting blend and thus, weight and content uniformity of tablets. The poor flowability and compactability of ESE and GSE could be the major challenges that need to be overcome to obtain the tablets of outstanding quality. Different direct compression excipients with different ratios were employed to improve the quality of EG tablets. This study, for the first time, reported the cause-effect relations and formulation optimization of the tablets containing ESE and GSE.

\section{MATERIALS AND METHODS}

\section{Materials}

ESE and GSE were obtained from BV Pharma JSC (Vietnam). SMCC (Prosolv® SMCC 90) and CCS (Vivasol®) were received from JRS
Pharma (Rosenberg, Germany) via Sapharchem Co., Ltd (Vietnam). Magnesium stearate (MS) was a gift from Brenntag (Denmark). DCPA (A-Tab®) was received from Innophos (Cranbury, NJ) via Asia Shine Co. Ltd. (Vietnam). Spray-dried lactose (SDL, Flowlac® 100) was kindly provided by Meggle Excipients and Technology (Wasserburg, Germany).

\section{Scanning electron microscopy}

The surface features and morphology of ESE, GSE and tablet blend were analyzed by using scanning electron microscopy (SEM) (JSMIT100, JEOL, Tokyo, Japan). A thin layer of each sample was placed on carbon double-sided adhesive tab, mounted onto a brass sample holder and sputter-coated with gold particles and observed under the microscope $[4,5]$. The SEM-images were taken with $1000 \mathrm{x}$ magnification. Images of tablet blend were also taken in order to investigate the arrangement of different particles in the blend before tableting.

\section{Particle size distribution}

The particle size and size distribution of ESE and GSE were separately evaluated by laser diffraction using a Master sizer 3000 (Malvern Instruments, Malvern, UK). The particle size was expressed as geometric median diameter based on a volume distribution $\left(\mathrm{d}_{50}\right)$, and the polydispersity of the samples was expressed by the span.

Effects of dilluents on the flowability of active ingredients

12 powder blends $\left(\mathrm{A}_{1}-\mathrm{A}_{12}\right)$ containing different dilluents (SMCC, DCPA, SDL) at different ratios $(40 \%, 50 \%, 60 \%$ and $70 \%, w / w)$ and 
active ingredients were prepared. Each powder mixture was then characterized its bulk density, tapped density, compressibility index and Hausner's ratio for evaluating the effects of diluents on the flowability of active ingredients.

\section{Characterization of powder}

$30 \mathrm{~g}$ powder was gently poured into a $100 \mathrm{ml}$ measuring cylinder and the volume $\left(\mathrm{V}_{\mathrm{o}}\right)$ occupied by the powder without tapping was recorded. After 200 taps on the table, the occupied volume (V) was read. Each experiment was carried out in triplicate. The bulk density $\left(\mathrm{d}_{\mathrm{o}}\right)$, tapped density (d), the compressibility index (CI) and Hausner's ratio $(\mathrm{H})$ were calculated using the following equations.

$$
\begin{gathered}
d_{s}=\frac{m}{V_{o}} \\
\mathrm{~d}=\frac{m}{V} \\
H=\frac{\mathrm{d}}{d_{\mathrm{o}}} \\
C I(\%)-\frac{\left(\mathrm{d}-d_{o}\right)}{\mathrm{d}} \times 100
\end{gathered}
$$

Where $\mathrm{m}$ is the total weight of the powder blend.

\section{Tablet preparation}

The EG tablets were prepared by using direct compression method. Ingredients (ESE, GSE, SMCC, DCPA, SDL and CCS) with different ratios were passed through 40 mesh sieve, weighed and mix well before adding magnesium stearate. Powder blend of each formulation was mixed by tumbling action and then compressed using a single-punch tableting machine (Riva Minipress MII, Riva, Germany) with an $11 \mathrm{~mm}$ diameter concave punch.

\section{Uniformity of tablet weight}

Twenty tablets from each batch were randomly chosen and individually weighed using a digital analytical balance (XB 220A; Precisa, Dietikon, Switzerland). The average weight of the tablets and percentage deviation of each individual tablet from the average weight were calculated.

\section{Hardness test}

The hardness of the EG tablet was determined by using a hardness tester (TBH 210, Erweka, Germany). Ten tablets from each batch were selected at random. Each tablet was placed radically between the jaws of the hardness tester and the diametral compression force was applied until the tablet broken. The average hardness and standard deviation were calculated.

\section{Friability test}

Friability was measured using a friability tester (Model: TA3B, Erweka, Germany). Ten tablets of each formulation were placed in a drum operated at $25 \mathrm{rpm}$ for $4 \mathrm{~min}$, following the standard USP 38 method [6]. The tablets were dedusted and weighed before and after using the tester to determine the loss in weight. Tablet friability was calculated using the following equation:

$$
\text { \% frabuhty }=\frac{W_{\mathrm{i}}-W_{f}}{W_{1}} \times 100
$$

Where $\mathrm{W}_{\mathrm{i}}$ and $\mathrm{W}_{\mathrm{f}}$ are the initial and final weights of all tablets, respectively. Less than or equal to $1 \%$ weight loss was considered acceptable.

\section{Disintegration time}

Tablet disintegration tests were carried out according to USP 38 [6]. Six tablets were separately placed into the basket-rack assembly of a disintegration apparatus (ZT 501, Erweka, Germany). The tablets were immersed into $900 \mathrm{ml}$ distilled water thermostatically maintained at $37 \pm 0.5{ }^{\circ} \mathrm{C}$. The time for complete disintegration of each tablet with no solid residue remained or only a trace amount of soft residue remained on the wire mesh was recorded. The disintegration time of each formulation was measured three times and the results were recorded as the mean \pm standard deviation.

\section{Experimental design and data analysis}

14 different formulations $\mathrm{F}_{1}-\mathrm{F}_{14}$ according to the D-optimal design were generated by Design Expert software (version 6.0.6, Stat-Ease Inc., Minneapolis, USA) to study the effects of independent variables on dependent variables. The constituents of the EG tablet formulations included ESE and GSE as active ingredients, mixtures of DCPA, SDL and SMCC as fillers whereas CCS and MS acted as superdisintegrant and lubricant, respectively.

Percentages of DCPA $\left(\mathrm{X}_{1}\right)$, \% SMCC $\left(\mathrm{X}_{2}\right)$ and \% CCS $\left(\mathrm{X}_{3}\right)$ were selected as three independent variables whereas weight variation $\left(\mathrm{Y}_{1}\right)$, disintegration time $\left(\mathrm{Y}_{2}\right)$, hardness $\left(\mathrm{Y}_{3}\right)$ and friability $\left(\mathrm{Y}_{4}\right)$ were chosen as four dependent variables. Percentage of DCPA $\left(\mathrm{X}_{1}\right)$ and \% CCS $\left(\mathrm{X}_{3}\right)$ were studied at three levels and \% SMCC $\left(\mathrm{X}_{2}\right)$ was studied at two levels. The selection ranges of independent variables were based on the results of initial trials.

All experiments were carried out in triplicate and the results were exhibited as mean \pm standard deviation. The data were then analyzed by BCPharSoft OPT software (Vietnam) and the best model was selected. The optimized formulation was obtained and repeated in triplicate for further validation. The predicted data created by BCPharSoft OPT software were compared with the observed response data of the optimized formulation using SPSS version 20.0 (SPSS, Inc., Chicago, IL, USA).

\section{RESULTS AND DISCUSSION}

\section{Morphology and particle size distribution of ESE and GSE}

Fig. 1 and fig. 2 show the morphology and particle size distribution of ESE and GSE, respectively. The SEM results revealed that the particles of ESE and GSE were in spherical or almost spherical shapes with smooth surfaces. The average diameters of ESE and GSE were found to be $22.4 \mu \mathrm{m}$ and $30.1 \mu \mathrm{m}$, respectively.

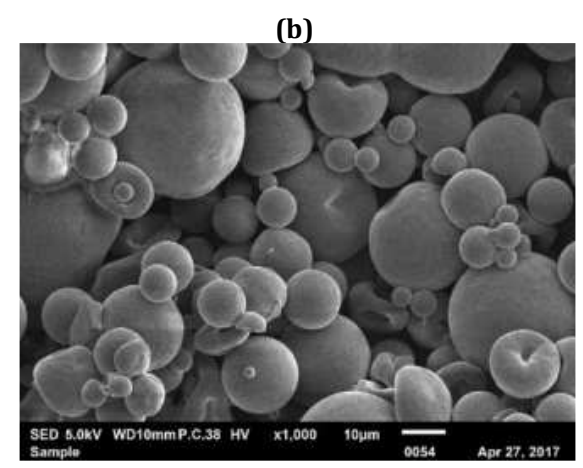

Fig. 1: SEM images of (a) ESE and (b) GSE 
As the general guide, the maximum angles of repose of powder close to $25^{\circ}$ correspond to excellent flow properties. The size and shape of the powders have been reported to influence their flowability. The larger, the more spherical the particles are, the better they flow [7]. ESE and GSE powders with angles of repose greater than $45^{\circ}$ were found to possess a very poor flowability in

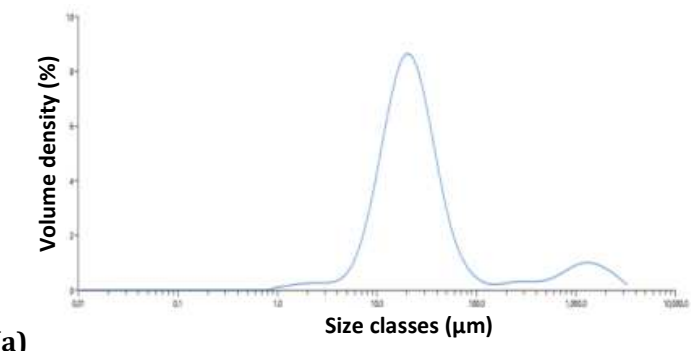

spite of their spherical shapes. This phenomenon could be explained by the cohesiveness of the small particles of ESE and GSE which caused by the electrostatic charge interactions. As a result, the ESE and GSE powder particles have tendancy to aggregate and obstruct the free-flowing of the two spray-dried extracts.

Fig. 2: Particle size distributions of (a) ESE and (b) GSE

\section{Effects of dilluents on the flowability of active ingredients}

The bulk density, tapped density, Hausner's ratio and the compressibility index of the investigated powder mixtures including active ingredients (blend of ESE and GSE at the ratio of 67:173, $\mathrm{w} / \mathrm{w}$ ) and different diluents are shown in table 1 .

The Hausner's ratio and the compressibility index of the investigated mixtures $\left(A_{1}-A_{12}\right)$ decreased when the percentages of the diluents increased. Therefore, the flowability of investigated mixtures was improved once the diluents were added. The bulk density and tapped density of the investigated mixtures increased due to the presence of the diluents which possess the higher densities and the rearrangement of particles in the powder mixtures. Due to the small particle size $(<35 \mu \mathrm{m})$,

\begin{abstract}
the large surface area of active ingredients allowed the increase in the surface area/volume ratio thus increasing the interparticulate attractive forces among themselves, causing the large friction forces and hence the poor flowability of the active ingredient powder. When being mixed with diluents identified with larger particle size (the aveage particle sizes of SMCC, DCPA and SDL were $121 \mu \mathrm{m}, 178 \mu \mathrm{m}$ and $135 \mu \mathrm{m}$, respectively), the active ingredient particles filled in the gaps between the contact surfaces of the large particles. When the diluents rolled or slided, the gravity forces could overcome interparticle forces such as the electrostatic or van der Waals interactions and hence led to the movement of active ingredient particles.
\end{abstract}

Therefore, the flowability of the investigated powder mixtures was improved.

Table 1: Properties of powder mixtures containing active ingredients and different diluents

\begin{tabular}{|c|c|c|c|c|c|c|c|c|c|}
\hline Formulation & $\begin{array}{l}\text { \% active ingredients } \\
\text { (w/w) }\end{array}$ & $\begin{array}{l}\text { \% DCPA } \\
(w / w)\end{array}$ & $\begin{array}{l}\text { \% } \\
\text { SMCC } \\
(w / w)\end{array}$ & $\begin{array}{l}\text { \% } \\
\text { SDL } \\
(w / w)\end{array}$ & $\begin{array}{l}\text { \% } \\
\text { MS } \\
\text { (w/w) }\end{array}$ & $\begin{array}{l}\mathrm{d}_{\mathrm{o}} \\
(\mathrm{g} / \mathrm{ml})\end{array}$ & $\begin{array}{l}\text { d } \\
(\mathrm{g} / \mathrm{ml})\end{array}$ & $\mathbf{H}$ & $\begin{array}{l}\text { CI } \\
(\%)\end{array}$ \\
\hline $\mathrm{A}_{1}$ & 59 & 40 & - & - & 1 & $0.42 \pm 0.003$ & $0.63 \pm 0.013$ & $1.49 \pm 0.021$ & $33.02 \pm 0.97$ \\
\hline $\mathrm{A}_{2}$ & 49 & 50 & - & - & 1 & $0.49 \pm 0.005$ & $0.69 \pm 0.009$ & $1.42 \pm 0.005$ & $29.35 \pm 0.28$ \\
\hline $\mathrm{A}_{3}$ & 39 & 60 & - & - & 1 & $0.56 \pm 0.003$ & $0.76 \pm 0.006$ & $1.37 \pm 0.535$ & $27.16 \pm 0.60$ \\
\hline $\mathrm{A}_{4}$ & 29 & 70 & - & - & 1 & $0.65 \pm 0.003$ & $0.83 \pm 0.003$ & $1.28 \pm 0.012$ & $21.74 \pm 0.90$ \\
\hline $\mathrm{A}_{5}$ & 59 & - & 40 & - & 1 & $0.34 \pm 0.003$ & $0.51 \pm 0.009$ & $1.47 \pm 0.014$ & $32.18 \pm 0.32$ \\
\hline $\mathrm{A}_{6}$ & 49 & - & 50 & - & 1 & $0.37 \pm 0.008$ & $0.52 \pm 0.003$ & $1.41 \pm 0.007$ & $29.07 \pm 0.35$ \\
\hline $\mathrm{A}_{7}$ & 39 & - & 60 & - & 1 & $0.38 \pm 0.003$ & $0.52 \pm 0.003$ & $1.39 \pm 0.361$ & $27.92 \pm 0.73$ \\
\hline $\mathrm{A}_{8}$ & 29 & - & 70 & - & 1 & $0.40 \pm 0.006$ & $0.52 \pm 0.006$ & $1.30 \pm 0.023$ & $23.33 \pm 0.92$ \\
\hline $\mathrm{A}_{9}$ & 59 & - & - & 40 & 1 & $0.38 \pm 0.003$ & $0.58 \pm 0.004$ & $1.53 \pm 0.011$ & $34.45 \pm 0.48$ \\
\hline $\mathrm{A}_{10}$ & 49 & - & - & 50 & 1 & $0.43 \pm 0.002$ & $0.61 \pm 0.002$ & $1.43 \pm 0.004$ & $30.12 \pm 0.21$ \\
\hline $\mathrm{A}_{11}$ & 39 & - & - & 60 & 1 & $0.48 \pm 0.002$ & $0.67 \pm 0.003$ & $1.38 \pm 0.012$ & $27.42 \pm 0.97$ \\
\hline $\mathrm{A}_{12}$ & 29 & - & - & 70 & 1 & $0.55 \pm 0.004$ & $0.70 \pm 0.004$ & $1.28 \pm 0.005$ & $21.82 \pm 0.90$ \\
\hline
\end{tabular}

Values are expressed as mean $\pm \operatorname{SD}(n=3)$.

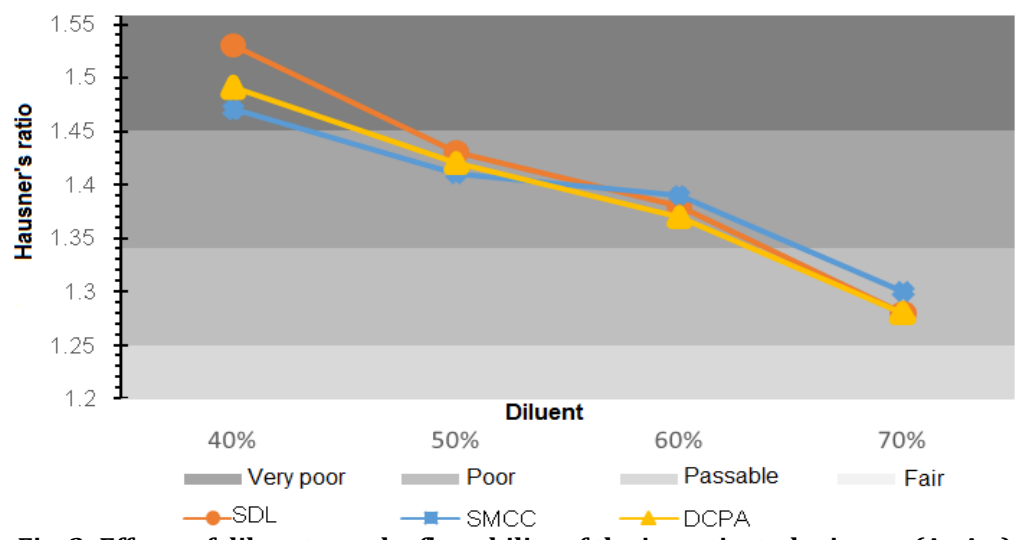

Fig. 3: Effects of diluents on the flowability of the investigated mixture ( $\left.A_{1}-A_{12}\right)$ 
The investigated mixture contained $40 \%$ SMCC as diluent showed the better flowability (lower Hausner's ratio) when compared with the investigated mixtures contained SDL or DCPA at the same ratio (fig. 3). The rough surfaces and irregular shapes of SMCC (fig. 4b) may leave more spaces for small particles of active ingredients to be adhered and hence improved the flowability of the investigated mixture better than DCPA and SDL with the almost spherical shapes (fig. $4 \mathrm{a}$ and fig. $4 \mathrm{c}$ ).

However, at the diluent ratios of $60 \%$ and $70 \%$, the investigated mixtures contained SDL or DCPA gave the lower Hausner's ratios and

(a)

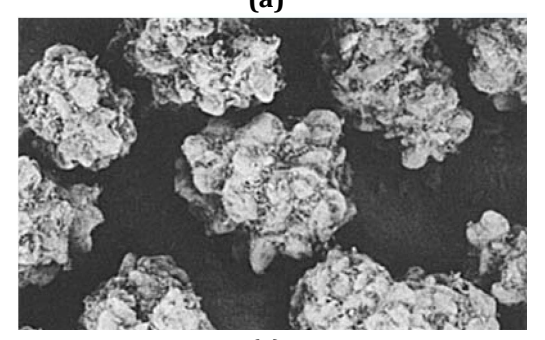

(c)

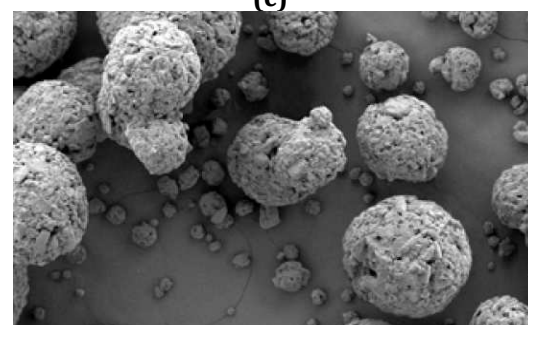

thus better flowability compared with the investigated mixture contained SMCC. It could be explained by the almost spherical shapes and the higher densities of SDL $(\mathrm{d}=0.71 \mathrm{~g} / \mathrm{ml})$ and DCPA $(\mathrm{d}=0.82$ $\mathrm{g} / \mathrm{ml}$ ). As a result, different mechanisms of flowability enhancement such as the optimized shape, density and size of particles should be employed for improving the flowability of the active ingredients.

\section{Optimization data analysis and validation of optimization model}

The levels of three independent variables and the constraints of the four dependent variables are shown in table 2 .

Fig. 4: SEM images of (a) DCPA; (b) SMCC; (c) SDL and (d) CCS

(b)

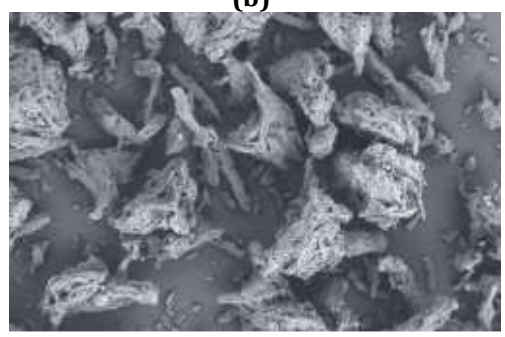

(d)

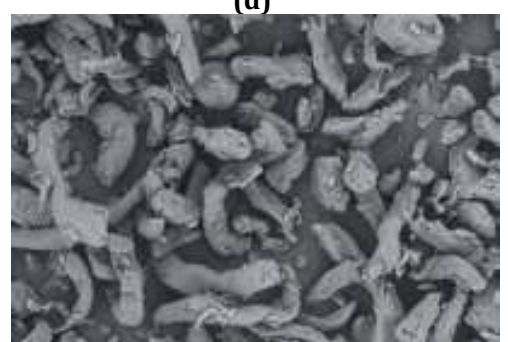

Table 2: Variables in experimental design

\begin{tabular}{lll}
\hline & Level & Medium \\
Independent variables & Low & 15 \\
$\mathrm{X}_{1}: \%$ DCPA $(\mathrm{w} / \mathrm{w})$ & 0 & 55 \\
$\mathrm{X}_{2}: \%$ SMCC $(\mathrm{w} / \mathrm{w})$ & 35 & 7 \\
$\mathrm{X}_{3}: \%$ CCS $(\mathrm{w} / \mathrm{w})$ & 0 & - \\
Dependent variables & Constraints & 14 \\
$\mathrm{Y}_{1}:$ Weight variation $(\%, \mathrm{w} / \mathrm{w})$ & Minimum & Minimum \\
$\mathrm{Y}_{2}:$ Disintegration time $(\mathrm{min})$ & Maximum \\
$\mathrm{Y}_{3}:$ Hardness $(\mathrm{N})$ & Minimum \\
$\mathrm{Y}_{4}:$ Friability $(\%, \mathrm{w} / \mathrm{w})$ & \\
\hline
\end{tabular}

Table 3 shows 14 formulations generated by Design Expert software. The ranges of weight variation $\left(\mathrm{Y}_{1}\right)$, disintegration time $\left(\mathrm{Y}_{2}\right)$, hardness $\left(\mathrm{Y}_{3}\right)$ and friability $\left(\mathrm{Y}_{4}\right)$ were found to be 1.15-2.34 \%, 11.7-21.42 min, 53.5-134.7 $\mathrm{N}$ and 0.155-0.683\%, respectively.

Table 3: The independent variables of 14 formulations $\left(F_{1}-F_{14}\right)$ and their responses

\begin{tabular}{lllllll}
\hline Formulation & \multicolumn{3}{l}{ Independent variables } & \multicolumn{3}{l}{ Dependent variables } \\
\cline { 2 - 7 } & $\mathbf{X}_{\mathbf{1}}$ & $\mathbf{X}_{\mathbf{2}}$ & $\mathbf{X}_{\mathbf{3}}$ & $\mathbf{Y}_{\mathbf{1}} \mathbf{( \% )}$ & $\mathbf{Y}_{\mathbf{2}} \mathbf{( m i n )}$ & $\mathbf{Y}_{\mathbf{3}} \mathbf{( N )}$ \\
\hline $\mathrm{F}_{1}$ & 0 & 35 & 7 & $2.12 \pm 0.20$ & $11.70 \pm 0.83$ & $95.5 \pm 10.1$ \\
$\mathrm{~F}_{2}$ & 15 & 35 & 14 & $1.82 \pm 0.47$ & $12.71 \pm 1.14$ & $67.8 \pm 5.3$ \\
$\mathrm{~F}_{3}$ & 15 & 55 & 14 & $1.50 \pm 0.24$ & $11.34 \pm 0.79$ & $58.1 \pm 6.1$ \\
$\mathrm{~F}_{4}$ & 30 & 35 & 14 & $2.34 \pm 0.99$ & $13.88 \pm 0.45$ & $61.6 \pm 4.1$ \\
$\mathrm{~F}_{5}$ & 30 & 55 & 14 & $1.45 \pm 0.13$ & $11.28 \pm 0.61$ & $53.5 \pm 2.0$ \\
$\mathrm{~F}_{6}$ & 15 & 55 & 0 & $1.41 \pm 0.41$ & $21.42 \pm 0.45$ & $108.5 \pm 3.7$ \\
$\mathrm{~F}_{7}$ & 0 & 35 & 14 & $1.83 \pm 0.41$ & $10.53 \pm 0.46$ & $61.8 \pm 5.6$ \\
$\mathrm{~F}_{8}$ & 0 & 35 & 0 & $1.39 \pm 0.37$ & $16.60 \pm 1.79$ & $127.8 \pm 13.7$ \\
$\mathrm{~F}_{9}$ & 15 & 35 & 7 & $1.67 \pm 0.13$ & $14.32 \pm 1.37$ & $96.7 \pm 1.2$ \\
$\mathrm{~F}_{10}$ & 0 & 55 & 0 & $1.67 \pm 0.71$ & $19.40 \pm 1.58$ & $102.9 \pm 0.9$ \\
$\mathrm{~F}_{11}$ & 15 & 35 & 0 & $1.49 \pm 0.19$ & $19.15 \pm 2.18$ & $134.7 \pm 16.6$ \\
$\mathrm{~F}_{12}$ & 0 & 55 & 7 & $1.49 \pm 0.27$ & $12.88 \pm 1.17$ & $73.1 \pm 1.5$ \\
$\mathrm{~F}_{13}$ & 30 & 55 & 7 & $1.56 \pm 0.17$ & $14.65 \pm 1.85$ & 0.026 \\
$\mathrm{~F}_{14}$ & 30 & 55 & 0 & $1.15 \pm 0.23$ & $11.70 \pm 0.83$ & 0.13 \\
\hline
\end{tabular}

$\mathrm{X}_{1}$ (\% DCPA); $\mathrm{X}_{2}$ (\% SMCC); $\mathrm{X}_{3}$ (\% CCS); $\mathrm{Y}_{1}$ (weight variation); $\mathrm{Y}_{2}$ (disintegration time); $\mathrm{Y}_{3}$ (hardness); $\mathrm{Y}_{4}$ (friability). Values are expressed as mean $\pm S D(n=3)$. 
Table 4: Composition of 14 formulations

\begin{tabular}{|c|c|c|c|c|c|c|c|c|c|c|c|c|c|c|}
\hline Ingredients & $\mathbf{F}_{1}$ & $\mathbf{F}_{2}$ & $F_{3}$ & $\mathbf{F}_{4}$ & $\mathbf{F}_{5}$ & $F_{6}$ & $F_{7}$ & $F_{8}$ & $F_{9}$ & $F_{10}$ & $F_{11}$ & $F_{12}$ & $F_{13}$ & $F_{14}$ \\
\hline ESE (mg) & 67 & 67 & 67 & 67 & 67 & 67 & 67 & 67 & 67 & 67 & 67 & 67 & 67 & 67 \\
\hline GSE (mg) & 173 & 173 & 173 & 173 & 173 & 173 & 173 & 173 & 173 & 173 & 173 & 173 & 173 & 173 \\
\hline DCPA $\left(\mathrm{X}_{1}\right)(\mathrm{mg})$ & 0 & 53 & 53 & 106 & 106 & 53 & 0 & 0 & 53 & 0 & 53 & 0 & 106 & 106 \\
\hline SMCC $\left(\mathrm{X}_{2}\right)(\mathrm{mg})$ & 124 & 124 & 195 & 124 & 195 & 195 & 124 & 124 & 124 & 195 & 124 & 195 & 195 & 195 \\
\hline $\operatorname{CCS}\left(\mathrm{X}_{3}\right)(\mathrm{mg})$ & 25 & 50 & 50 & 50 & 50 & 0 & 50 & 0 & 25 & 0 & 0 & 25 & 25 & 0 \\
\hline SDL (mg) & 205 & 127 & 57 & 74 & 4 & 106 & 181 & 230 & 152 & 159 & 177 & 135 & 28 & 53 \\
\hline MS (mg) & 6 & 6 & 6 & 6 & 6 & 6 & 6 & 6 & 6 & 6 & 6 & 6 & 6 & 6 \\
\hline Total (mg) & 600 & 600 & 600 & 600 & 600 & 600 & 600 & 600 & 600 & 600 & 600 & 600 & 600 & 600 \\
\hline
\end{tabular}

The compositions of 14 formulations are shown in table 4 . The data in table 4 were used as inputs for BCPharSoft OPT to study on the cause-effect relations and optimize the EG tablet formulation.

Training parameters were set at:

-Test groups: $Y_{1}(1,6), Y_{2}(5,6), Y_{3}^{(3,8)}$ and $Y_{4}{ }^{(1,8)}$

-Transfer function: Back Propagation Learning

Table 5: Model statistics from BCPharSoft OPT outputs

\begin{tabular}{lll}
\hline Dependent variables & $\mathbf{R}^{2}$ training & $\mathbf{R}^{2}$ test \\
\hline $\mathrm{Y}_{1}$ & 0.99 & 1.00 \\
$\mathrm{Y}_{2}$ & 0.99 & 1.00 \\
$\mathrm{Y}_{3}$ & 0.99 & 1.00 \\
$\mathrm{Y}_{4}$ & 0.99 & 1.00 \\
\hline
\end{tabular}

Table 5 shows that all $\mathrm{R}^{2}$ training and $\mathrm{R}^{2}$ test values were more than 0.9 indicated the very good reliability of the models and these models could be used for multivariate optimization.

The three-dimensional (3D) response surface plots of the fit models were depicted for better understanding of the cause-effect relationships between the independent and dependent variables. Each 3D diagram illustrated the effects of two independent variables on the dependent variables at one time while the third variable was kept constant.

\section{Effects of variables on weight variation}

When $\mathrm{X}_{2}$ (\% SMCC) was more than $45 \%$, the weight variation of EG tablets $\left(Y_{1}\right)$ was low (fig. 5a). An increase in $X_{2}$ (\% SMCC) caused the decrease in weight variation $\left(\mathrm{Y}_{1}\right)$ while \% DCPA $\left(\mathrm{X}_{1}\right)$ did not have significant influences on weight variation $\left(\mathrm{Y}_{1}\right)$. This could be explained by the rough surfaces of SMCC which led to more active ingredient particles to be adhered, caused the flowability enhancement of the powder mixtures and improved

\section{(a)}

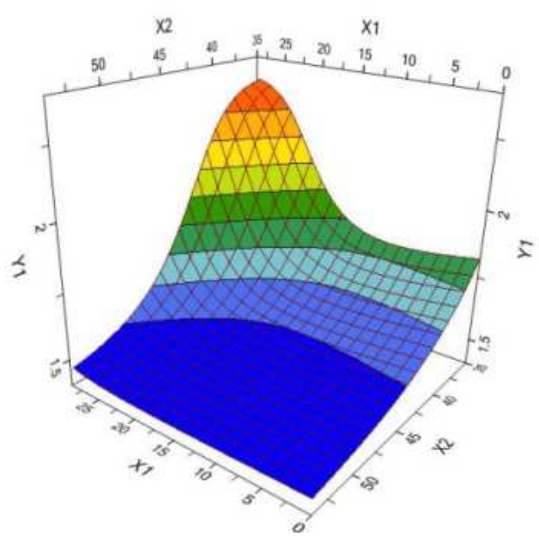

the EG tablet uniformity and hence reduced the weight variation $\left(\mathrm{Y}_{1}\right)$.

Fig. 5a shows that when \% SMCC $\left(\mathrm{X}_{2}\right)$ was lower than $45 \%$, an increase in \% DCPA $\left(\mathrm{X}_{1}\right)$ resulted in higher weight variation $\left(\mathrm{Y}_{1}\right)$. The same result was also reported in the study of Zhang Y [8]. Among the three employed diluents, DCPA has the highest density which could cause the signification difference in density between DCPA and the other ingredients in the powder mixtures and led to the poor powder flowability and thus the higher weight variation $\left(\mathrm{Y}_{1}\right)$.

When \% SMCC $\left(\mathrm{X}_{2}\right)$ was less than $45 \%$, an increase in \% CCS $\left(\mathrm{X}_{3}\right)$ led to an increase in weight variation ( $\mathrm{Y}_{1}$ ) (fig. $5 \mathrm{~b}$ ). CCS has the small particle size, the low density and the long shape (fig. $4 \mathrm{~d}$ ) which could cause the poor flowability of the tableting powder mixtures and an increase in weight variation $\left(\mathrm{Y}_{1}\right)[9,10]$.

Fig. 5: Response surface plots showing the effects of (a) \% DCPA $\left(\mathrm{X}_{1}\right)$ and \% SMCC $\left(\mathrm{X}_{2}\right)$ on weight variation $\left(\mathrm{Y}_{1}\right)$; (b) \% SMCC ( $\left.\mathrm{X}_{2}\right)$ and \% CCS $\left(\mathrm{X}_{3}\right)$ on weight variation $\left(\mathrm{Y}_{1}\right)$

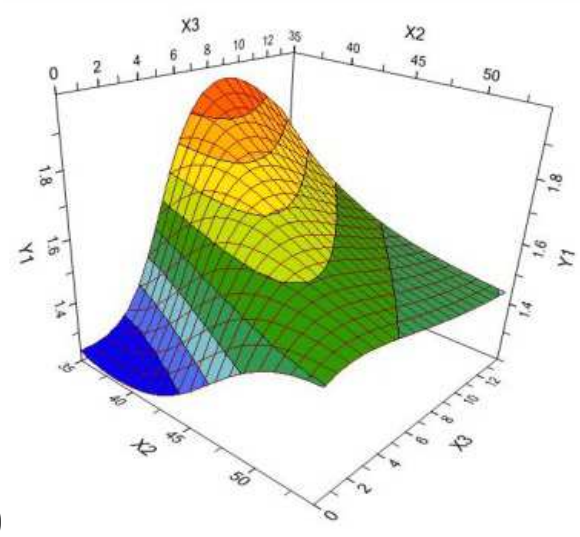

(b)

has the nature of cellulose making itself could uptake water, increase the tablet volume and made the tablet disintegrated faster and thus also acted as a disintegrant [11]. The same result was also reported in the study of Kachrimanis K [12].

When \% SMCC $\left(\mathrm{X}_{2}\right)$ increased, the disintegration time $\left(\mathrm{Y}_{2}\right)$ decreased (fig. 6a). SMCC is the silicified microcrystalline cellulose, therefore, it 
Fig. $6 \mathrm{~b}$ depicts that an increase in \% CCS $\left(\mathrm{X}_{3}\right)$ caused a decrease in disintegration time $\left(\mathrm{Y}_{2}\right)$. CCS is a superdisintegrant which draws water into tablets. When contacting with water, CCS swelled,

(a)

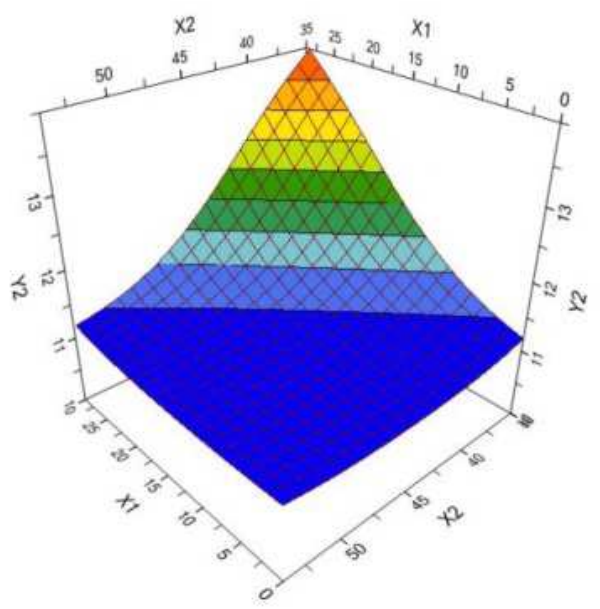

significantly increased in the volume and caused the tablets to break apart [13]. The same results were also found in the study of Ferrero C [14] and Shakar AAM [11].

Fig. 6: Response surface plots showing the effects of (a) \% DCPA $\left(X_{1}\right)$ and \% SMCC $\left(X_{2}\right)$ on disintegration time $\left(Y_{2}\right)$; (b) \% DCPA $\left(X_{1}\right)$ and \% CCS $\left(\mathrm{X}_{3}\right)$ on disintegration time $\left(\mathrm{Y}_{2}\right)$

\section{Effects of variables on hardness}

Fig. 7a shows that the hardness $\left(\mathrm{Y}_{3}\right)$ decreased as \% SMCC $\left(\mathrm{X}_{2}\right)$ increased. The same result was also reported in the study of Van Veen B [15]. The rule could be explained by the elastic deformation of SMCC which may not create the new surfaces during the compression process. Moreover, due to the silicified layer covered the SMCC particles, the interactions between SMCC and the other particles in the tableting blend could be reduced and led to the reduction of hardness $\left(\mathrm{Y}_{3}\right)$.

It could be observed from fig. 7 a that hardness $\left(\mathrm{Y}_{3}\right)$ increased with \% DCPA $\left(\mathrm{X}_{1}\right)$. The increase in hardness ( $\left.\mathrm{Y}_{3}\right)$ could be

(a)

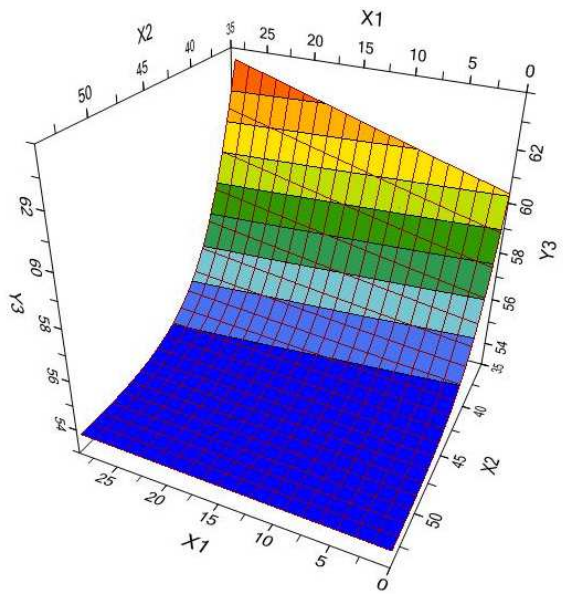

explained by the brittle deformation of DCPA which created new surfaces, reduced the particle size and rearranged the tableting blend.

Hardness data (table 3 ) show that the formulations containing $14 \%$ CCS $\left(F_{2}, F_{3}, F_{4}, F_{5}, F_{7}\right)$ had the low hardness. Ferrero $C[14]$ and Solaiman A [16] reported that CCS had the negative effect on tablet hardness. This could be explained by the nature of CCS which has the elastic deformation causing the weak binding between themselves and others particles. As a result, an increase in CCS $\left(\mathrm{X}_{3}\right)$ could cause the decrease in hardness $\left(\mathrm{Y}_{3}\right)$ (fig. 7b). (b)

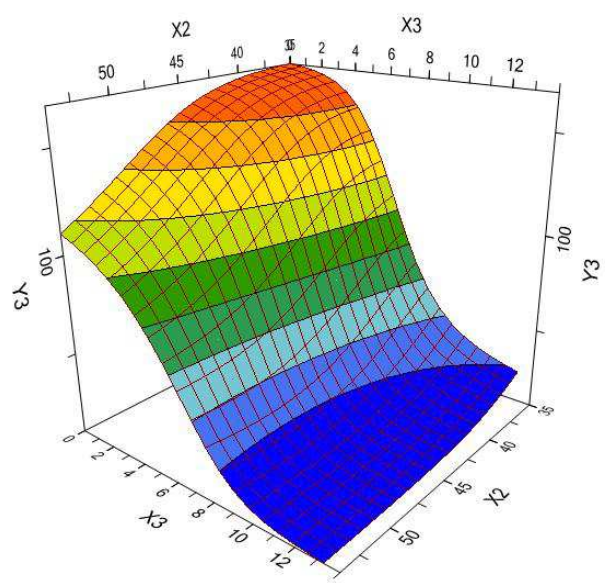

Fig. 7: Response surface plots showing the effects of (a) \% DCPA $\left(X_{1}\right)$ and \% SMCC $\left(X_{2}\right)$ on hardness ( $\left.Y_{3}\right) ;(b) \%$ SMCC $\left(X_{2}\right)$ and \% CCS $\left(X_{3}\right)$ on hardness $\left(\mathrm{Y}_{3}\right)$

\section{Effect of variables on friability}

It is evident from fig. 8 that when \% DCPA $\left(\mathrm{X}_{1}\right)$ was higher than $15 \%$, the tablet friability $\left(\mathrm{Y}_{4}\right)$ increased propotionally with \% SMCC $\left(\mathrm{X}_{2}\right)$. The rough surface and irregular shapes of SMCC particles caused more porosities and cavities which reduced the compression efficiency. Moreover, SMCC also had the elastic deformation caused the decrease in tablet hardness and the increase in tablet friability. Therefore, the rough surface, the irregular shapes and the elastic deformation could be the main reasons causing the high friability $\left(\mathrm{Y}_{4}\right)$ of the tablet.

When \% DCPA $\left(\mathrm{X}_{1}\right)$ was lower than $15 \%$, friability $\left(\mathrm{Y}_{4}\right)$ decreased when $\%$ DCPA $\left(\mathrm{X}_{1}\right)$ increased. The deformation mechanism of excipients could affect the tablet hardness and thus the tablet friability. DCPA with the brittle deformation could be broken into the smaller pieces with new surfaces. The smaller pieces may fill the gaps between the particles and the new surfaces may create the tablet with lower friability. 


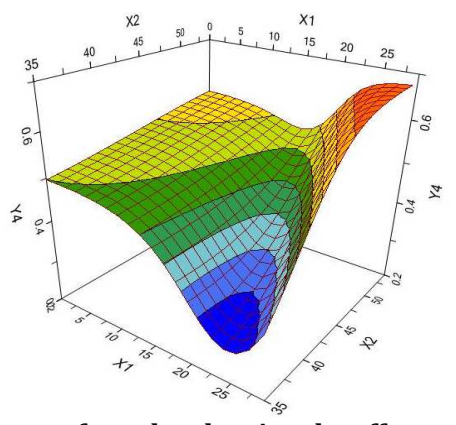

Fig. 8: Response surface plot showing the effects of \% DPCA $\left(X_{1}\right)$ and \% SMCC $\left(\mathrm{X}_{2}\right)$ on the friability $\left(\mathrm{Y}_{4}\right)$ of EG tablet $(\mathrm{n}=3)$

\section{Optimization of EG tablet formulation}

The optimized EG tablet formulation was achieved by BCPharSoft OPT software with $40 \%$ active ingredients (blend of ESE and GSE at the ratio of $67: 173, \mathrm{w} / \mathrm{w}$ ) and $60 \%$ excipients including DCPA, SMCC and CCS at the percentages of $9 \%, 35 \%$ and $14 \%$, respectively. In order to confirm the validity of the optimization procedure, three replicated batches of the optimized EG tablet formulation were prepared and statistically compared with the predicted data using one sample T-test (table 6). Weight variation $\left(\mathrm{Y}_{1}\right)$, disintegration time $\left(\mathrm{Y}_{2}\right)$, hardness $\left(\mathrm{Y}_{3}\right)$ and friability $\left(\mathrm{Y}_{4}\right)$ of the optimized EG tablet were found to be at $1.66 \pm 0.08 \%$, $12.44 \pm 1.18 \mathrm{~min}, 61.9 \pm 3.7 \mathrm{~N}$ and $0.43 \pm 0.05 \%$, respectively. It was demonstrated that all predicted values were in good agreement with the observed values ( $p>0.05)$.

Table 6: Comparison of the predicted and observed responses of the optimized EG tablet formulation

\begin{tabular}{lllll}
\hline Responses & $\mathbf{Y}_{\mathbf{1}}(\mathbf{\%})$ & $\mathbf{Y}_{\mathbf{2}} \mathbf{( m i n )}$ & $\mathbf{Y}_{\mathbf{3}}(\mathbf{N})$ & \\
\hline Predicted & 1.8 & 11.7 & 61.4 & \\
Observed & $1.66 \pm 0.08$ & $12.44 \pm 1.18$ & $61.9 \pm 3.7$ & 0.5 \\
P-values & 0.100 & 0.389 & 0.819 & $0.43 \pm 0.05$ \\
\hline
\end{tabular}

Values are expressed as mean $\pm \operatorname{SD}(n=3)$.

Particle interactions in the tableting blend of the optimized EG tablet formulation

SEM images from fig. 9 revealed the mechanical entanglements due to the shape, size and roughness of the particles in the tableting blend of the optimized EG tablet formulation. The small spherical particles of the active ingredients tended to dispose on the surfaces of the bigger particles (excipients) and rough surface particles more than smooth one. As a result, the friction of rough particles was decreased. The particles of excipients (bigger sizes) were dispersed, indicating a lack of cohesive interactions between them. This could be the major mechanism for improving the flowability of the active ingredients.
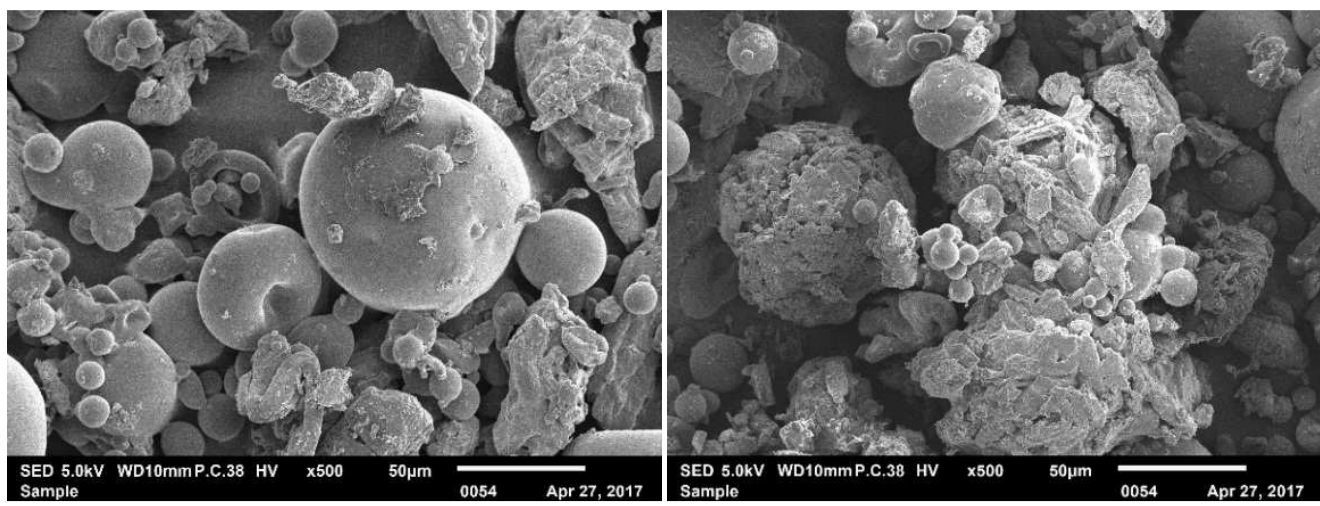

Fig. 9: SEM images of the optimized EG tablet blend (x500)

\section{CONCLUSION}

The ESE and GSE could be formulated into tablet by using direct compression method with a total percentage of active ingredients up to $40 \%(\mathrm{w} / \mathrm{w})$. The effects of three independent variables (\% DCPA, $\%$ SMCC and \% CCS) on four dependent variables (weight variation, disintegration time, hardness and friability of EG tablet) were investigated. All investigated independent variables were demonstrated the significant effects on all dependent variables and the cause-effects relationships were raised up. The optimized EG tablet formulation contained $40 \%$ active ingredients (blend of ESE and GSE at the ratio of $67: 173, \mathrm{w} / \mathrm{w}$ ) and $60 \%$ excipients including DCPA, SMCC and CCS at the percentages of $9 \%, 35 \%$ and $14 \%$, respectively.

\section{AUTHORS CONTRIBUTIONS}

There are four authors who contribute to this manuscript. The percentages of contribution of Vo Thanh Hoa, Bui Thi Thu Huong, Do Quang Duong, and Nguyen Duc Hanh are 10\%, 35\%, 10\%, and 45\%, respectively.

\section{CONFLICT OF INTERESTS}

All authors declare that this article content has no conflict of interest

\section{REFERENCES}

1. Gallo L, Ramirez-Rigo MV, Pina J, Palma S, Allemandi D, Bucala V. Valeriana officinalis dry plant extract for direct compression: preparation and characterization. Sci Pharm 2012;80:1013-26.

2. Erum S, Hassan F, Hasan SMF, Jabeen S. Formulation of aspirin tablets using fewer excipients by direct compression. Pak J Pharmcol 2011;28:31-7.

3. Tong HH, Wong SY, Law MW, Chu KW, Chow AH. Antihygroscopic effect of dextrans in herbal formulations. Int J Pharm 2008; 363:99-105.

4. Utami D, Nugrahani I, Ibrahim S. Mefenamic acid-nicotinamide co-crystal synthesized by using melt crystallization method and its solubility study. Asian J Pharm Clin Res 2017;10:135-9.

5. Chaiyasut C, Sivamaruthi BS, Makhamrueang N, Kesika P, Sirilun S, Peerajan S. Preparation and stability assessment of Perilla frutescens seed oil powder. Asian J Pharm Clin Res 2017;10:366-9. 
6. The United States Pharmacopeial Convention, Rockville, MD: USP 38: The United States Pharmacopeia Convention; 2015.

7. Tomas J, Kleinschmidt S. Improvement of flowability of fine cohesive powders by flow additive. Chem Eng Technol 2009; 32:1470-83.

8. Zhang Y, Law Y, Chakrabarti S. Physical properties and compact analysis of commonly used direct compression binders. AAPS PharmSciTech 2003;4:489-99.

9. Rojas J, Kumar V. Comparative evaluation of silicified microcrystalline cellulose II as a direct compression vehicle. Int J Pharm 2011;416:120-8.

10. Rojas J, Kumar V. Effect of silicification on the tableting performance of cellulose II: a novel multifunctional excipient. Chem Pharm Bull 2012;60:603-11.

11. Shakar AAM, Razzak MSMI, Hossain MM, Arif MH, Reza MS. Effect of superdisintegrants on some physical attributes and release profile of paracetamol immediate release tablets. Bangladesh Pharm J 2012;15:89-94.
12. Kachrimanis K, Nikolakakis I, Malamataris S. Tensile strength and disintegration of tableted silicified microcrystalline cellulose: influences of interparticle bonding. J Pharm Sci 2003;92:1489-501.

13. Mohanachandran PS, Sindhumol PG, Kiran TS. Superdisintegrants: an overview. Int J Pharm Sci Rev Res 2011;6:105-9.

14. Ferrero C, Munoz N, Velasco MV, Munoz-Ruiz AR, JimenezCastellanos R. Disintegrating efficiency of croscarmellose sodium in a direct compression formulation. Int J Pharm 1997;147:11-21.

15. Van Veen B, Bolhuis GK, Wu YS, Zuurman K, Frijlink HW. Compaction mechanism and tablet strength of unlubricated and lubricated (silicified) microcrystalline cellulose. Eur J Pharm Biopharm 2005;59:133-8.

16. Solaiman A, Suliman AS, Shinde S, Naz S, Elkordy AA Application of general multilevel factorial design with formulation of fast disintegrating tablets containing croscaremellose sodium and disintequick MCC-25. Int J Pharm 2016;501:87-95. 